\title{
Borrelia sinica sp. nov., a Lyme disease-related Borrelia species isolated in China
}

1 Department of Microbiology, School of Pharmaceutical Sciences, University of Shizuoka, Shizuoka, 422-8526, Japan

2 Department of Immunology and Medical Zoology, Fukui Medical University, Fukui 910-1193, Japan

3 Fukui Prefectural Institute of Public Health, Fukui 910-8551, Japan

4 Department of Microbiology, School of Medicine, Gifu University, Gifu, 500-8705, Japan

\author{
Toshiyuki Masuzawa, ${ }^{1}$ Nobuhiro Takada, ${ }^{2}$ Midori Kudeken, ${ }^{1}$ \\ Takako Fukui, ${ }^{1}$ Yasuhiro Yano, ${ }^{2}$ Fubito Ishiguro, ${ }^{3}$ Yoshiaki Kawamura, ${ }^{4}$ \\ Yasuyuki Imai ${ }^{1}$ and Takayuki Ezaki ${ }^{4}$
}

Author for correspondence: Toshiyuki Masuzawa. Tel: +8154264 5710. Fax: +81542645715. e-mail:masuzawa@u-shizuoka-ken.ac.jp

\begin{abstract}
A survey was performed for Lyme disease borrelia in the southern part of China, in Zhejiang, Sichuan and Anhui provinces, along the Yangtze River valley, in May of 1997 and 1998. Twenty isolates from Ixodes granulatus, Ixodes ovatus, Apodemus agrarius and Niviventer confucianus were obtained. These isolates were characterized by RFLP of the 5S-23S rDNA intergenic spacer, sequence analysis of the intergenic spacer, 16S rDNA and flagellin gene, DNA-DNA hybridization analysis, SDS-PAGE and Western blotting with mAbs. Six isolates from $A$. agrarius, five from $I$. granulatus collected in Zhejiang province and one from $\boldsymbol{N}$. confucianus in Sichuan province were highly similar to strains 10MT and 5MT isolated in Korea and classified as Borrelia valaisiana. Four isolates from $A$. agrarius and $I$. granulatus collected in Zhejiang province generated unique RFLP patterns and phylogenetic analysis of the 165 rDNA and flagellin gene sequences suggested that the isolates should be classified as $B$. valaisiana. Furthermore, three isolates (CMN1a, CNM2, CMN3') from $N$. confucianus captured in Sichuan province and one (CWO1) from I. ovatus in Anhui province showed lower 16S rDNA sequence similarity (less than $\mathbf{9 9 . 0 \% )}$ to sequences of previously described Lyme diseaserelated Borrelia species. DNA-DNA hybridization results revealed that strains $\mathrm{CMN3}^{\top}$ and CMN1a were clearly distinct from all other known Lyme disease Borrelia species. Electron microscope observation showed the spirochaetes to be morphologically similar to those of Borrelia, but the cells contained only four periplasmic flagella inserted at each end of the spirochaetes. Based on these results, a new Borrelia species, Borrelia sinica sp. nov., is proposed. Strain $\mathrm{CMN}^{\mathrm{T}}$ is the type strain of this new species.
\end{abstract}

Keywords: Borrelia sinica, Borrelia valaisiana, China, Ixodes ovatus, Lyme disease

\section{INTRODUCTION}

Lyme borreliosis is the most prevalent tick-borne zoonotic disease in Europe, North America and FarEastern countries such as Japan, Russia and China (Steere, 1989). The causative agent, Borrelia burgdorferi (Johnson et al., 1984), was isolated from the tick Ixodes dammini (Burgdorfer et al., 1982). B.

Abbreviations: Hsp, heat-shock protein; Osp, outer surface protein. The DDBJ accession numbers for the 16S rDNA, flagellin gene and 5S-235 rDNA intergenic spacer sequences reported in this paper are $A B 022101$ and AB022124-AB022146. burgdorferi sensu lato is classified into 10 species: $B$. burgdorferi sensu stricto, isolated in North America and Europe; Borrelia garinii (Baranton et al., 1992) and Borrelia afzelii (Canica et al., 1993), isolated in Europe and east Asian countries; Borrelia japonica, Borrelia tanukii and Borrelia turdi, respectively isolated from Ixodes ovatus, Ixodes tanuki and Ixodes turdi in Japan (Fukunaga et al., 1996; Kawabata et al., 1993); 'Borrelia andersonii', isolated from Ixodes dentatus in North America (Marconi et al., 1995); Borrelia valaisiana (Wang et al., 1997) and Borrelia lusitaniae (Le Fleche et al., 1997), isolated from Ixodes ricinus in Europe; and 'Borrelia bissettii' (Postic et al., 1998), isolated in North America. Furthermore, B. valaisiana 
has been found in Korea, Taiwan and Japan (Kee et al., 1996; Masuzawa et al., 1999, 2000; Wang et al., 1997).

We previously performed a survey in the north-eastern part of China and isolates from Ixodes persulcatus and from the rodent Apodemus peninsulae were identified as $B$. afzelii and $B$. garinii, but no isolates were determined as B. burgdorferi sensu stricto ( $\mathrm{Li}$ et al., 1998). In order to examine the prevalence of Lyme disease Borrelia and to discover new Borrelia species, we performed a survey in the southern part of China in 1997 and 1998. Consequently, 20 isolates were obtained from Ixodes granulatus, I. ovatus, Apodemus agrarius and Niviventer confucianus. The aim of this study was to characterize these isolates based on their genetic and phenotypic properties. On the basis of the results of the present study, we propose that isolates from $N$. confucianus captured in Sichuan province and I. ovatus collected in Anhui province should be described as Borrelia sinica sp. nov.

\section{METHODS}

Survey sites and isolation of Borrelia. The Borrelia isolates from China are listed in Table 1. Ticks and wild rodents were collected in the southern part of China, from Zhejiang, Sichuan and Anhui provinces, in May of 1997 and 1998. Ixodid ticks were collected by dragging vegetation at woodland areas. At the same time, wild rodents were also captured in Sherman live traps. Spirochaetes were isolated from earlobe tissues of rodents (A. agrarius and $N$. confucianus) and the midgut of two species of tick (I. granulatus and I. ovatus) by the method described previously (Takada et al., 1998) and were cultivated at $30^{\circ} \mathrm{C}$ in BarbourStoenner-Kelly II medium (Barbour, 1984).

PCR and RFLP analysis of 5S-23S rDNA intergenic spacer. Primers corresponding to the $3^{\prime}$ end of the 5S rDNA ( $r r f$ ) (5'-CTGCGAGTTCGCGGGAGA-3') and the 5' end of the 23S rDNA $(r r l)$ (5'-TCCTAGGCATTCACCATA-3') (Masuzawa et al., 1996a; Postic et al., 1994) were synthesized. PCR was performed by the method described previously (Postic et al., 1994). The amplification products of 5S-23S rDNA amplicons were digested with MseI and DraI and the digested DNA was electrophoresed through $16 \%$ polyacrylamide gels. DNA bands were visualized by ethidium bromide staining.

Sequencing of 5S-23S rDNA intergenic spacer, the flagellin gene and 16S rDNA. 16S rDNA sequences and flagellin genes were amplified with primer pairs $16 \mathrm{SF} 1\left(5^{\prime}\right.$-ATAACGAAGAGTTTGATCCTGGC-3') and 16SR (5'-CAGCCGCACTTTCCAGTACG-3'), corresponding to the $5^{\prime}$ and $3^{\prime}$ ends of the 16S rDNA, and flaF (5'-GATTATAAATCATAATAGGTCAGC-3') and flaR2 (5'-CTCCTCAATAAGCCTGCATTATGC-3'), corresponding to the $5^{\prime}$ and $3^{\prime}$ ends of fla. The amplicons from 16S rDNA (about $1350 \mathrm{bp}$ ), the flagellin gene (about $970 \mathrm{bp}$ ) and the intergenic spacer sequence (about $250 \mathrm{bp}$ ) were cloned into the pGEM-T vector and the recombinant plasmids were transformed into Escherichia coli JM109 using the pGEM-T vector system (Promega) according to the manufacturer' instructions. The

Table 1. RFLP analysis of the 5S-23S rRNA intergenic spacer

Taxa are listed as reported previously or as identified in this study.

\begin{tabular}{|c|c|c|c|c|c|}
\hline \multirow[t]{2}{*}{ Strain } & \multirow[t]{2}{*}{ Isolated from: } & \multirow[t]{2}{*}{ Location } & \multicolumn{3}{|c|}{ Size (bp) } \\
\hline & & & Amplicon & DraI fragments & MseI fragments \\
\hline \multicolumn{6}{|l|}{ B. valaisiana } \\
\hline CKA2a*, CKA3b*, CKA5b & A. agrarius & Hangzhou, Zhejiang & 254 & 173,81 & $150,58,24,22$ \\
\hline $\begin{array}{l}\text { CKG1, CKG2, CKG3, CKG5, } \\
\text { CKG6 }\end{array}$ & I. granulatus & Hangzhou, Zhejiang & $\sim 250$ & CKA2a type & CKA2a type \\
\hline CMN1b & N. confucianus & Nanchuan, Sichuan & $\sim 250$ & CKA2a type & CKA2a type \\
\hline CKA2b*, CKA4a, CKA4b & A. agrarius & Hangzhou, Zhejiang & 254 & 173,81 & $107,58,43,24,22$ \\
\hline CKA ${ }^{*}$, CKA $5 \mathrm{a}$ & A. agrarius & Hangzhou, Zhejiang & 253 & $144,52,29,28$ & $145,51,29,21,7$ \\
\hline CKA3a* & A. agrarius & Hangzhou, Zhejiang & 246 & 144,102 & $145,59,28,14$ \\
\hline CKG4 & I. granulatus & Hangzhou, Zhejiang & $\sim 250$ & CKA1 type & CKA1 type \\
\hline \multicolumn{6}{|l|}{ Borrelia sinica sp. nov. } \\
\hline $\mathrm{CMN}^{\mathrm{T} *}$ & N. confucianus & Nanchuan, Sichuan & 235 & $157,49,29$ & $107,48,38,29,13$ \\
\hline CMN1a*, CMN2 & N. confucianus & Nanchuan, Sichuan & 236 & $144,50,42$ & $107,49,38,29,13$ \\
\hline $\mathrm{CWO}^{*}$ & I. ovatus & Mt Huangshan, Anhui & 236 & $144,50,42$ & $107,49,38,29,13$ \\
\hline \multicolumn{6}{|l|}{ Reference strains } \\
\hline B. valaisiana $\mathrm{VS} 116^{\mathrm{T} *}$ & I. ricinus & Switzerland & 255 & 203,52 & $174,51,23,7$ \\
\hline B. valaisiana $10 \mathrm{MT}^{*}$ & I. nipponensis & Korea & 254 & 173,81 & $150,58,24,22$ \\
\hline B. valaisiana $5 \mathrm{MT}^{*}$ & I. nipponensis & Korea & 254 & 173,81 & $107,58,43,24,22$ \\
\hline
\end{tabular}

* Exact fragment sizes were determined from the sequences. Sequences of strains CKA2a (accession no. AB022124), CKA3b (AB022125), CKA2b (AB022126), CKA1 (AB022127), CKA3a (AB022128), CMN1a (AB022129), CWO1 (AB022130) and CMN3 ${ }^{\mathrm{T}}$ (AB022131) were determined in this study. Previously published sequences, deposited with the following accession numbers, were also utilized: VS116 ${ }^{\mathrm{T}}$ (L30134), 5MT (AB013914) and 10MT (AB013915). 


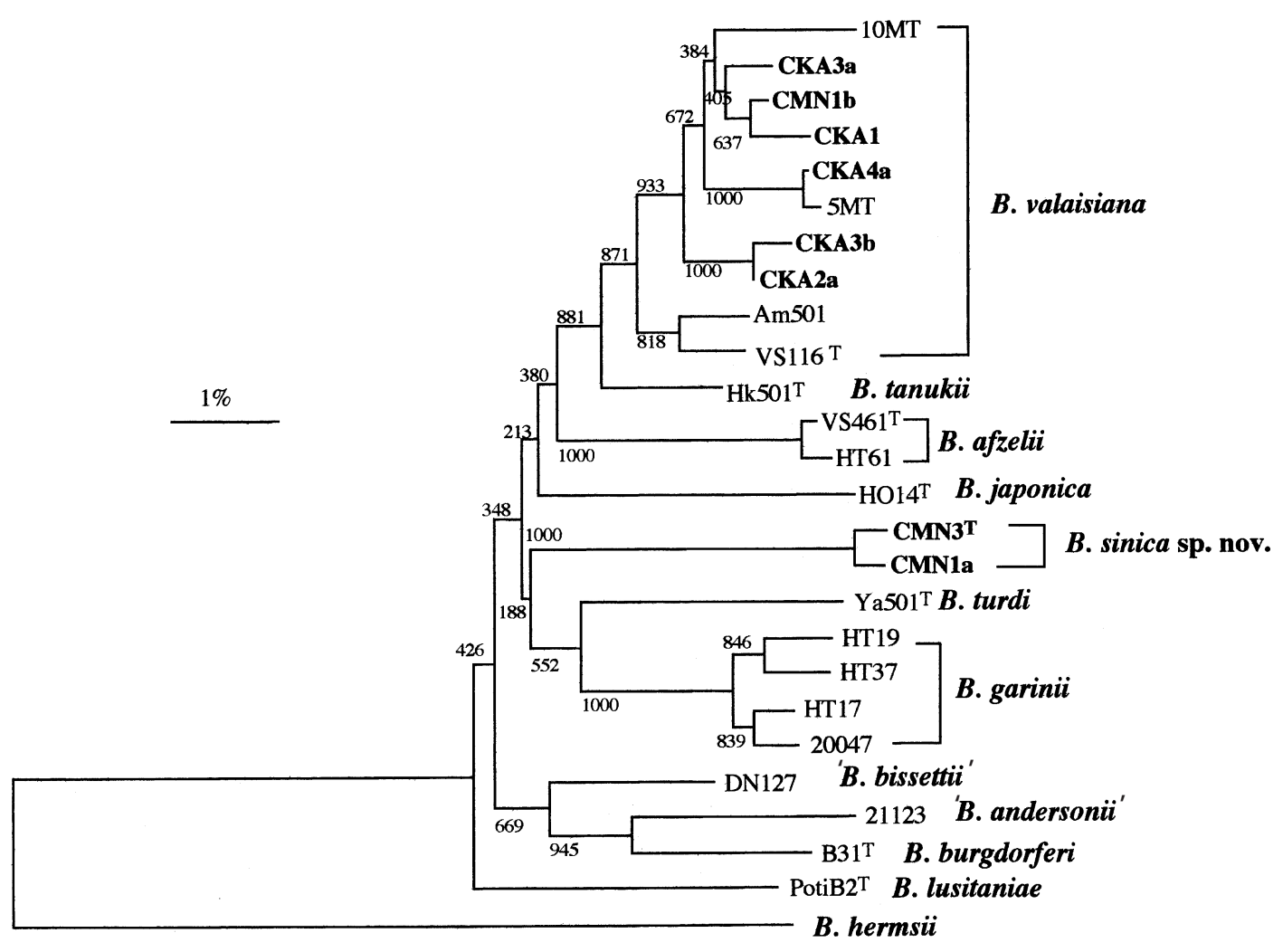

Fig. 1. Phylogenetic tree based on flagellin gene sequences. Sequences of strains CKA1 (accession no. AB022132), CKA2a (AB022133), CMN1b (AB022134), CKA3a (AB022135), CKA4a (AB022136), CMN1a (AB022137), CMN3 ${ }^{\top}$ (AB022138) and CKA3b (AB022139) were determined in this study. Previously published sequences, deposited with the following accession numbers, were also utilized: VS116 ${ }^{\top}$ (D82854), 10MT (AB014678), 5MT (AB014677), Am501 (D82855), B31 (X15661), 20047 ${ }^{\top}$ (D82846), HT17 (D63363), HT19 (D63371), HT37 (D63369), VS461 ${ }^{\top}$ (D63365), HT61 (D63366), $\mathrm{HO}^{\top}{ }^{\top}$ (D82852), 21123 (D83764), $\mathrm{Hk}^{2}$ (D1 $^{\top}$ (D82847), Ya501 ${ }^{\top}$ (D82849), PotiB2 ${ }^{\top}$ (D85856), DN127 (D82857) and the relapsing fever borrelia, Borrelia hermsii strain HS1 (M86838). Bar, sequence divergence of $1.0 \%$. Chinese isolates are indicated in bold type.

recombinant plasmids were extracted from $E$. coli cultures using a Plasmid Miniprep kit (Bio-Rad) and sequenced by the dideoxy chain-termination method using a Taq DyeDeoxy Terminator cycle sequencing kit with primers M13 (-29) and M13 reverse and a model 373A DNA sequencer (Applied Biosystems) or Sequi Them EXEL II Long-Read DNA sequencing kit LC (Epicentre Technology) and LICOR 4000 DNA sequencer. At least three clones were sequenced.

Nucleotide sequence accession numbers. The intergenic spacer, flagellin gene and 16S rDNA sequences were submitted to DDBJ, EMBL and GenBank with the accession numbers listed in the legends to Figs 1 and 2 and in Table 1.

Phylogenetic analysis. The CLUSTAL X software, originally described by Thompson et al. (1997), was used to align the sequences and phylogenetic distances were calculated by the neighbour-joining method (Saitou \& Nei, 1987). The phylogenetic tree was drawn using NJplot software. Bootstrap values were obtained with 1000 resamplings.

Determination of DNA-DNA hybridization. DNAs were extracted and purified from strains $\mathrm{CMN}^{\mathrm{T}}$ and $\mathrm{CMN1a}$ and 10 strains of B. burgdorferi sensu lato species by the method described previously (Kawabata et al., 1993). Purified reference DNAs were used to determine DNA-
DNA hybridization by the microplate hybridization method (Ezaki et al., 1988; Kawabata et al., 1993). Aliquots containing $1 \mu \mathrm{g}$ heat-denatured DNA solution were incubated for $12 \mathrm{~h}$ at $37^{\circ} \mathrm{C}$ in microdilution plates (Dynatech Laboratories). The DNA solution was discarded and then dried overnight at $60{ }^{\circ} \mathrm{C}$. Two-hundred microlitres of prehybridization solution $[2 \times \mathrm{SSC}(1 \times \mathrm{SSC}$ is $0.15 \mathrm{M} \mathrm{NaCl}$ plus $0 \cdot 015 \mathrm{M}$ sodium citrate), $5 \times$ Denhardt's solution, $50 \%$ formamide] containing $200 \mu \mathrm{g}$ denatured salmon sperm DNA ml ${ }^{-1}$ was added to microdilution wells that had been coated with reference DNAs. The microdilution plates were incubated at $37^{\circ} \mathrm{C}$ for $1 \mathrm{~h}$ and then washed. Photobiotinlabelled DNA was prepared as described previously (Ezaki et al., 1989) and $50 \mathrm{ng}$ labelled DNA was then added. Hybridization was performed with hybridization solution $(2 \times \mathrm{SSC})$ containing $50 \%$ formamide at $26^{\circ} \mathrm{C}$ (Blüthmann et al., 1973). After hybridization, the microdilution plates were washed with $2 \times$ SSC buffer. Streptavidin- $\beta$-Dgalactosidase (Gibco) was added to the wells and incubated at $37^{\circ} \mathrm{C}$ for $30 \mathrm{~min}$. After incubation, the wells were washed and 4-methylumbelliferyl $\beta$-D-galactopyranoside (Wako) was added as substrate. After incubation, the fluorescence intensity was measured with a MicroFluor reader (Dynatech Laboratories) at a wavelength of $360 \mathrm{~nm}$ for excitation and $450 \mathrm{~nm}$ for emission. The experiment was performed in triplicate. 


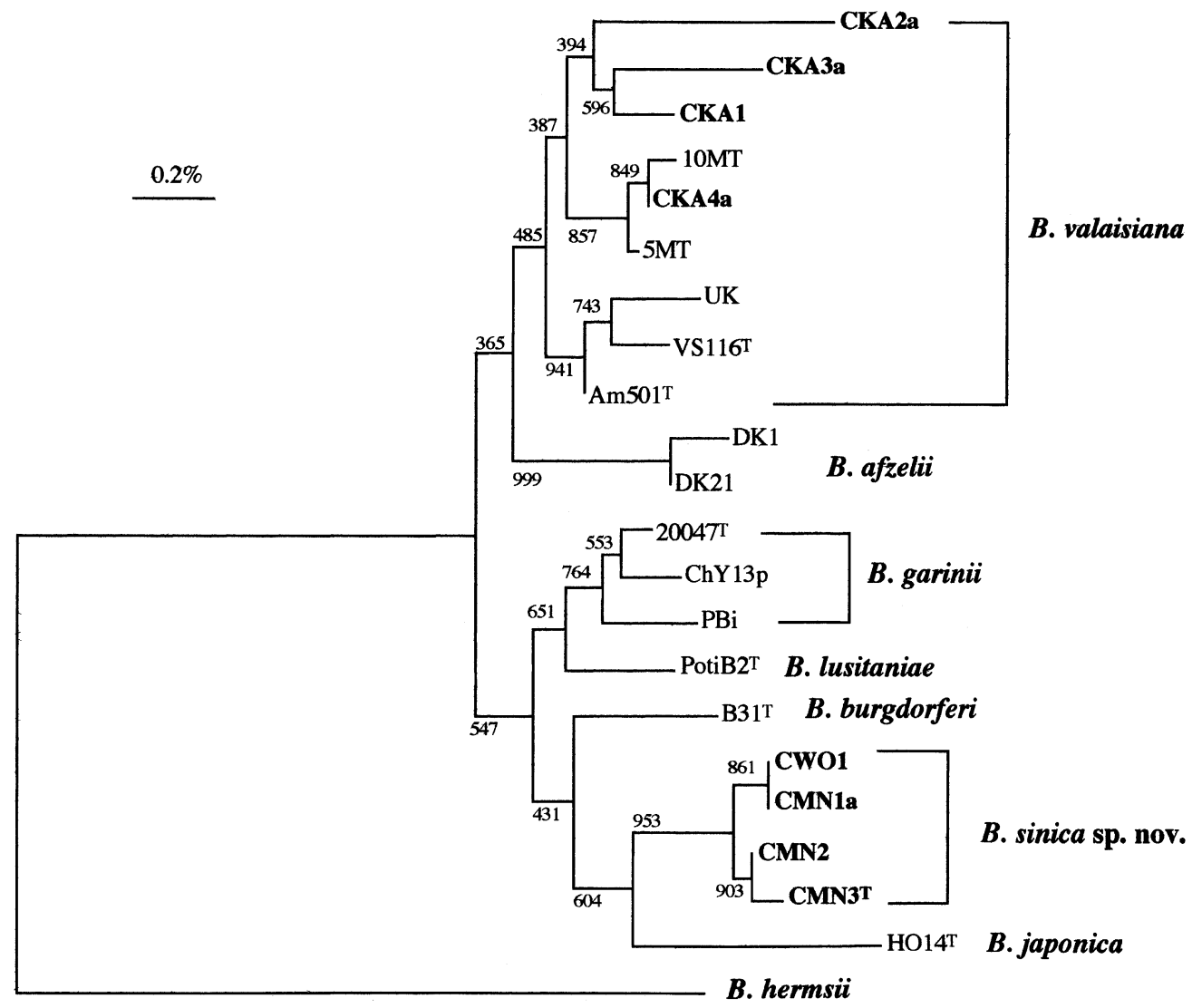

Fig. 2. Phylogenetic tree based on $16 \mathrm{~S}$ rDNA sequences. Sequences of strains $C N M 3^{\top}$ (AB022101), CKA3a (AB022140), CKA1 (AB022141), CKA2a (AB022142), CKA4a (AB022143), CMN1a (AB022144), CMN2 (AB022145) and CWO1 (AB022146) were determined in this study. Previously published sequences, deposited with the following accession numbers, were also utilized: 5MT (U44938), 9MT (L39080), 10MT (AB016974), VS116 ${ }^{\top}$ (X98232), UK (X98233), Am501 (D67021), B31 (B59293), DK21 (X85191), 20047 (D67018), PBi (X85199) and B. hermsii strain HS1 (U42292). Bar, sequence divergence of $0 \cdot 2 \%$. Chinese isolates are indicated in bold type.

SDS-PAGE and Western blotting. SDS-PAGE and Western blotting were carried out according to methods described previously (Masuzawa et al., 1991). After electrophoresis, the gels were stained with Coomassie brilliant blue. Antigens were transferred onto PVDF membranes (Bio-Rad) and specific antigen bands were subsequently detected by immunostaining with mAbs. The mAbs used were: H9724 and O1441b to flagellin; LA2, H5332, P31b, P31c and P31d to outer surface protein A (OspA) (Masuzawa et al., 1996c); G7 to OspC (Masuzawa et al., 1996b); O62a to heat-shock protein 60 (Hsp60) (Masuzawa et al., 1996c); and D6 to $12 \mathrm{kDa}$ antigen (Baranton et al., 1992).

Electron microscopy. To prepare negatively stained specimens, a drop of the cell suspension concentrated by centrifugation was allowed to adsorb onto carbon-coated Formvar film supported on copper grids. The cells were stained with $2 \%$ sodium phosphotungstate for $30 \mathrm{~s}$. The specimens were examined with a Hitachi H-7000 electron microscope at an acceleration voltage of $100 \mathrm{kV}$. To determine the numbers of flagella, cross-sections of Borrelia cells were prepared. Aliquots of $5 \mathrm{ml}$ borrelial culture (strains CMN1a and CMN3 ${ }^{\mathrm{T}}$ ) in BSK II medium were fixed by addition of an equal volume of $4 \%(\mathrm{v} / \mathrm{v})$ glutaraldehyde in $0.1 \mathrm{M}$ cacodylate buffer $(\mathrm{pH} 7 \cdot 4)$ for $6 \mathrm{~h}$ at $4{ }^{\circ} \mathrm{C}$. The cells were harvested by centrifugation, washed gently in buffer and post-fixed with cold $1 \%$ osmium tetroxide for $3.5 \mathrm{~h}$. The pellet was mixed with $0.5 \mathrm{ml} 2 \%$ agarose. The agarose blocks were dehydrated in graded acetone and embedded in epoxy resin. Ultrathin sections were doubly stained with uranyl acetate and lead acetate before observation with a Hitachi H-600 electron microscope at an acceleration voltage of $75 \mathrm{kV}$.

G $+\mathbf{C}$ contents of DNAs. DNA base compositions were determined by HPLC (Noguchi et al., 1988) using a DNAGC kit (Yamasa Shoyu).

\section{RESULTS AND DISCUSSION}

\section{RFLP analysis and sequencing of the 5S-23S rDNA intergenic spacer}

The results of RFLP analysis of the $5 \mathrm{~S}-23 \mathrm{~S}$ rDNA intergenic spacer sequence are summarized in Table 1. Exact fragment sizes generated after digestion with restriction enzymes DraI and $M s e I$ were determined by sequencing analysis of the amplicon. Eight strains (CKA2a, CKA3b, CKG1, CKG2, CKG3, CKG5, 
Table 2. DNA-DNA relatedness of $B$. sinica sp. nov. and other species of $B$. burgdorferi sensu lato

\begin{tabular}{|c|c|c|c|c|c|c|}
\hline \multirow[t]{2}{*}{ Strain } & \multicolumn{6}{|c|}{ Level of DNA relatedness with labelled DNA from: } \\
\hline & 1 & 2 & 3 & 4 & 5 & 6 \\
\hline 1. $\mathrm{CMN}^{\mathrm{T}}$ & $100 \cdot 0$ & $75 \cdot 8$ & $36 \cdot 5$ & $41 \cdot 7$ & $59 \cdot 7$ & $54 \cdot 3$ \\
\hline 2. CMN1a & $84 \cdot 9$ & $100 \cdot 0$ & $57 \cdot 8$ & $59 \cdot 8$ & $58 \cdot 2$ & $54 \cdot 8$ \\
\hline 3. B. burgdorferi $\mathrm{B} 31^{\mathrm{T}}$ & $58 \cdot 5$ & $34 \cdot 0$ & $100 \cdot 0$ & $35 \cdot 2$ & $38 \cdot 7$ & $32 \cdot 6$ \\
\hline 4. B. garinii $20047^{\mathrm{T}}$ & $52 \cdot 5$ & $66 \cdot 5$ & $48 \cdot 7$ & $100 \cdot 0$ & $53 \cdot 8$ & $49 \cdot 3$ \\
\hline 5. B. tanukii Fi81t & $50 \cdot 8$ & $59 \cdot 6$ & $52 \cdot 3$ & $53 \cdot 8$ & $100 \cdot 0$ & $61 \cdot 2$ \\
\hline 6. B. japonica $\mathrm{HO}^{2} 4^{\mathrm{T}}$ & $52 \cdot 1$ & $59 \cdot 8$ & $49 \cdot 5$ & $57 \cdot 0$ & $67 \cdot 9$ & $100 \cdot 0$ \\
\hline 7. B. afzelii $\mathrm{VS} 461^{\mathrm{T}}$ & $43 \cdot 1$ & $54 \cdot 4$ & $45 \cdot 9$ & $57 \cdot 0$ & $57 \cdot 4$ & $45 \cdot 7$ \\
\hline 8. B. turdi $\mathrm{Ya} 501^{\mathrm{T}}$ & $46 \cdot 4$ & $61 \cdot 7$ & $48 \cdot 5$ & $60 \cdot 3$ & $57 \cdot 4$ & $51 \cdot 0$ \\
\hline 9. 'B. andersonii' 21123 & $38 \cdot 8$ & $49 \cdot 5$ & $69 \cdot 9$ & $55 \cdot 7$ & $52 \cdot 4$ & $47 \cdot 0$ \\
\hline 10. B. valaisiana $\mathrm{VS} 116^{\mathrm{T}}$ & $30 \cdot 4$ & $49 \cdot 3$ & $61 \cdot 5$ & $59 \cdot 7$ & $62 \cdot 5$ & $59 \cdot 6$ \\
\hline 11. B. lusitaniae PotiB2 ${ }^{\mathrm{T}}$ & $47 \cdot 4$ & $64 \cdot 8$ & $47 \cdot 3$ & $65 \cdot 4$ & $51 \cdot 4$ & $46 \cdot 3$ \\
\hline 12. 'B. bissettii' DN127 & $47 \cdot 0$ & $46 \cdot 8$ & $72 \cdot 8$ & $45 \cdot 2$ & $49 \cdot 9$ & $47 \cdot 1$ \\
\hline
\end{tabular}

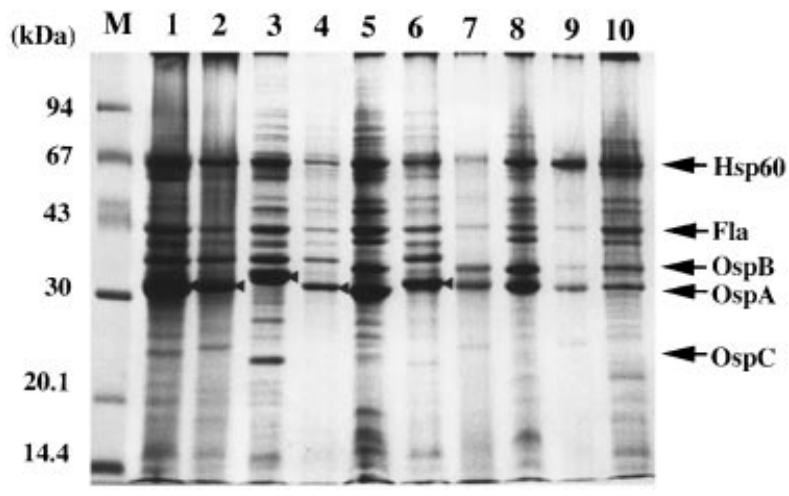

Fig. 3. SDS-PAGE profiles of Chinese Borrelia strains. Lanes: $M$, molecular mass markers; 1, CKA1; 2, CKA2a; 3, CKA3a; 4, CKA3b; 5, CMN1a; 6, CMN1b; 7, CMN2; 8, CMN3 ${ }^{\top} ; 9$, CWO1; $10, \mathrm{~B} 31^{\top}$. Ten micrograms of protein was applied to each lane of the $12.5 \%$ polyacrylamide gel. Arrowheads indicate the position of OspA reactive to $\mathrm{mAb}$ P31c.

CKG6 and CKA5b) isolated from $A$. agrarius and $I$. granulatus collected in Hangzhou, Zhejiang province, and one isolate (CMN1b) from $N$. confucianus in Nanchuan, Sichuan province, generated RFLP patterns identical to that of strain 10MT, isolated from Ixodes nipponensis collected in Korea. Three isolates (CKA2b, CKA4a, CKA4b) from A. agrarius collected in Zhejiang province showed patterns identical to that of strain 5MT, also isolated from I. nipponensis collected in Korea. Kee et al. (1996) tentatively classified Korean strains 10MT and 5MT as belonging to the $B$. afzelii-related genomic group on the basis of $16 \mathrm{~S}$ rDNA gene sequences. The strains showed higher similarity to $B$. valaisiana than to $B$. afzelii in their $16 \mathrm{~S}$ rDNA sequences and were distinguishable from $B$. afzelii by RFLP analysis of the intergenic spacer sequence (Masuzawa et al., 1999). Consequently, we classified these Chinese isolates as B. valaisiana. The other eight strains listed in Table 1 generated unique RFLP patterns that could be differentiated from those of species reported previously (Masuzawa et al., 1999).

\section{Phylogenetic analysis based on flagellin gene sequences}

A phylogenetic tree based on flagellin gene sequences (Fig. 1) was constructed on the basis of a sequencesimilarity matrix of the flagellin gene. The sequences of the six strains CKA2a, CMN1b, CKA3b, CKA4a, CKA1 and CKA3a showed higher similarity values, ranging from $97 \cdot 1$ to $99 \cdot 7 \%$, to strains $5 \mathrm{MT}, 10 \mathrm{MT}$, Am501 and VS116 ${ }^{\mathrm{T}}$ and were clustered with these strains. Strains CMN1a and CMN3 ${ }^{\mathrm{T}}$, isolated from $N$. confucianus captured in Sichuan, diverged from $B$. valaisiana and other previously described species.

\section{Phylogenetic analysis of 16S rDNA sequences}

A phylogenetic tree based on 16S rDNA sequences (Fig. 2) was constructed on the basis of a sequencesimilarity matrix (1367 bp). The sequences of the four strains CKA1, CKA2a, CKA3a and CKA4a clustered with $B$. valaisiana strains VS116 ${ }^{\mathrm{T}}$, UK, Am501, 10MT and 5MT and showed the highest similarity to strains of this group, ranging from $98 \cdot 8$ to $99 \cdot 9 \%$.

Strains CMN1a, CMN2, CWO1 and CMN3 ${ }^{\mathrm{T}}$ showed relatively lower similarity to previously described species, whereas these strains showed high levels of similarity to each other, ranging from $99 \cdot 8$ to $100 \%$. These observations suggested that these isolates were different from previously described species.

\section{DNA-DNA hybridization}

Chromosomal DNA-DNA hybridization values among strains of $10 \mathrm{~B}$. burgdorferi sensu lato species are shown in Table 2. The levels of DNA relatedness of 
Table 3. Reactivity of the isolates with various mAbs

The targets of the various mAbs tested are indicated in parentheses. All strains tested reacted with mAbs O62a (Hsp60) and H9724 (flagellin). NT, Not tested.

\begin{tabular}{|c|c|c|c|c|c|c|c|c|c|}
\hline Strain & Isolated in: & $\begin{array}{l}\text { O1441b } \\
\text { (flagellin) }\end{array}$ & $\begin{array}{l}\text { P31b } \\
\text { (OspA) }\end{array}$ & $\begin{array}{l}\text { P31c } \\
\text { (OspA) }\end{array}$ & $\begin{array}{l}\text { P31d } \\
\text { (OspA) }\end{array}$ & $\begin{array}{l}\text { H5332 } \\
\text { (OspA) }\end{array}$ & $\begin{array}{c}\text { LA2 } \\
\text { (OspA) }\end{array}$ & $\begin{array}{c}\text { G7 } \\
(\text { OspC) }\end{array}$ & $\begin{array}{c}\text { D6 (12 kDa } \\
\text { antigen) }\end{array}$ \\
\hline \multicolumn{10}{|l|}{ B. sinica sp. nov. } \\
\hline $\begin{array}{l}\mathrm{CMN}^{\mathrm{T}}, \mathrm{CMN} 1 \mathrm{a}, \\
\mathrm{CMN} 2, \mathrm{CWO} 1\end{array}$ & China & - & - & - & - & - & - & + & - \\
\hline \multicolumn{10}{|l|}{ B. valaisiana } \\
\hline CKA1, CKA2a & China & - & - & + & - & - & - & + & - \\
\hline CKA3a, CKA3b & China & - & - & + & - & + & - & + & - \\
\hline CMN1b & China & - & - & + & - & - & - & - & - \\
\hline $5 \mathrm{MT}$ & Korea & - & - & + & - & NT & NT & + & NT \\
\hline $10 \mathrm{MT}$ & Korea & - & - & + & - & NT & NT & + & NT \\
\hline VS116 $6^{\mathrm{T}}$ & Switzerland & - & - & - & - & NT & NT & + & NT \\
\hline Am501 & Japan & - & - & - & - & NT & NT & + & NT \\
\hline B. burgdorferi $\mathrm{B} 31^{\mathrm{T}}$ & USA & - & - & - & - & + & + & + & - \\
\hline B. garinii HP1 & Japan & - & + & + & - & - & - & + & + \\
\hline B. afzelii $\mathrm{PGau}$ & Germany & - & - & + & + & - & - & + & - \\
\hline B. japonica $\mathrm{HO} 14^{\mathrm{T}}$ & Japan & + & - & + & - & - & - & + & - \\
\hline
\end{tabular}

strains $\mathrm{CMN}^{\mathrm{T}}$ and CMN1a were less than $70 \%$ when compared with the type strains of 10 species described previously. This result indicated that strains $\mathrm{CMN}^{\mathrm{T}}$ and CMN1a were not members of previously known species.

\section{Protein profiles and reactivity with mAbs}

Strains classified as $B$. valaisiana showed variable molecular masses of OspA and OspB. Likewise, four strains of the novel taxon had variable sizes of proteins that seemed to be OspA and OspB, ranging from 31 to $35 \mathrm{kDa}$ (Fig. 3). All Chinese strains tested reacted with mAbs H9724 to flagellin and 062a to Hsp60, which are specific to Borrelia species or B. burgdorferi sensu lato, but did not react with $\mathrm{O} 1441 \mathrm{~b}$, specific for flagellin of $B$. japonica, LA2, specific for OspA of B. burgdorferi sensu stricto, D6, specific for B. garinii, or P31d, specific for OspA of B. afzelii (Table 3). Chinese isolates classified as $B$. valaisiana reacted with $\mathrm{mAb}$ $\mathrm{P} 31 \mathrm{c}$, specific for OspA, as did Korean strains 5MT and $10 \mathrm{MT}$, members of $B$. valaisiana. No reactivity of strains $\mathrm{CMN}^{\mathrm{T}}$, CMN1a, CMN2 or CWO1 was observed with mAbs reactive to OspA in this study. This result suggested that the four strains differed from known species. However, the group of Borrelia could not be identified and distinguished by SDS-PAGE protein profiles alone.

\section{Morphology}

On electron microscope observation of negatively stained specimens, the cells showed the characteristic borrelial shape, i.e. a helical shape with tapered ends.
The length of the cells was variable, about $10-25 \mu \mathrm{m}$, and the diameter was $0 \cdot 25-0 \cdot 3 \mu \mathrm{m}$ (Fig. 4a). The maximum number of flagella observed at the tapered end of the cells was four. An insertion point was observed in the preparation (Fig. 4b). In order to determine the number of flagella, cross-sections of Borrelia cells were prepared; two to four flagella were observed within the ridge (Fig. 4c-f). These results suggested that cells of the novel taxon have two to four flagella at each end. Cells of B. burgdorferi sensu lato have approximately seven to fourteen flagella at each end (Burgdorfer et al., 1982; Hovind-Hougen et al., 1986; Oliver et al., 1993; Yano et al., 1997; Zung et al., 1989). Barbour \& Hayes (1986) clearly demonstrated seven periplasmic flagellar insertion points in the terminus portion of B. burgdorferi. The number of flagella in these novel isolates was thus very low in comparison with other borrelial species. Since the flagella are generally responsible for motility, the number of flagella may also affect their movement. In fact, these isolates cannot move actively in medium and readily developed into cell clusters in medium (data not shown); therefore, the exact doubling time could not be determined.

\section{$\mathbf{G}+\mathbf{C}$ content of DNA}

The $\mathrm{G}+\mathrm{C}$ content of the DNA of strain $\mathrm{CMN}^{\mathrm{T}}$, isolated from $N$. confucianus, was $29 \cdot 6 \mathrm{~mol} \%$. This value is in agreement with those reported previously for B. burgdorferi sensu lato (Barbour \& Hayes, 1986; Johnson et al., 1984; Kawabata et al., 1993). From these findings, a new Borrelia species, Borrelia sinica sp. nov., was designated. 

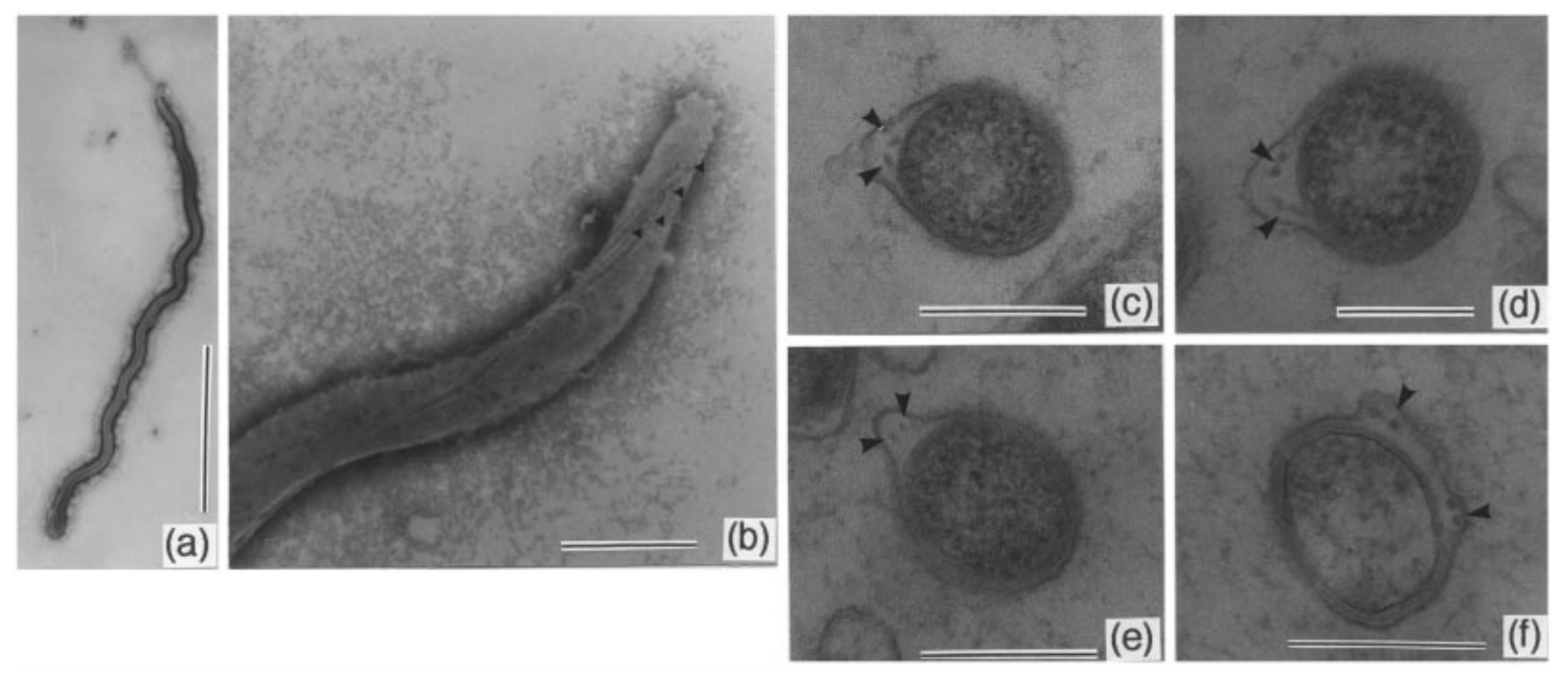

Fig. 4. Electron micrographs of $B$. sinica sp. nov. (a) Morphology of a negatively stained cell of $B$. sinica strain CMN3 ${ }^{\top}$. Bar, $5.0 \mu \mathrm{m}$. (b) Negatively stained cell of $B$. sinica strain $\mathrm{CMN3}^{\top}$ showing insertion points of flagella marked by arrowheads. Bar, $0.5 \mu \mathrm{m}$. (c)-(d) Cross-sections of cells of $B$. sinica strain CMN3 ${ }^{\top}$ bearing two (c) or four (d) flagella, indicated by arrowheads. Bars, $0.2 \mu \mathrm{m}$. (e)-(f) Cross-sections of cells of $B$. sinica strain CMN1a bearing two (e) or four (f) flagella, indicated by arrowheads. Bars, $0.2 \mu \mathrm{m}$.

\section{Description of Borrelia sinica sp. nov.}

Borrelia sinica (si'ni.ca. L. fem. adj. sinica of China, the country from which the organisms were isolated).

Morphology was as described previously for the genus (Burgdorfer \& Hayes, 1986). However, counting of flagella showed a maximum of four at each end. Cultivated in BSK II medium at $30-34{ }^{\circ} \mathrm{C}$, similar to B. burgdorferi (Johnson et al., 1984). Differentiated from other B. burgdorferi sensu lato species by analysis of $\mathrm{DraI}$ and $\mathrm{MseI}$ restriction polymorphism of the 5S-23S rDNA $(r r f-r r l)$ spacer. The $\mathrm{G}+\mathrm{C}$ content of the DNA is $29.6 \mathrm{~mol} \%$ for the type strain.

The type strain, $\mathrm{CMN}^{\mathrm{T}}$, has been deposited in the Japan Collection of Microorganisms (RIKEN) as strain JCM $10505^{\mathrm{T}}$. This strain was isolated from $N$. confucianus captured in Sichuan province, China.

\section{ACKNOWLEDGEMENTS}

We thank Drs Ma (Zhejiang Institute of Microbiology), H. Fujita (Ohara Hospital) and H. Ohtake (Miyagi Prefectural University of Agriculture) for help with the survey in China. We also thank Dr K. Tsuchiya (Miyazaki Medical University) for identification of rodents. We are grateful to Drs A. G. Barbour (University of California), E. Isogai (Health Science University of Hokkaido), D. Postic (Institut Pasteur) and O. Péter (Institut Central des Hopitaux Valaisans) for providing mAbs. This study was supported in part by Grants-in-Aid for International Cooperative Research (nos 08044310, 08041181 and 10041204) and Grants-in-Aid for Scientific Research (nos 07670320, 08670312, 09670294 and 11670267) from the Ministry of Education, Science and Culture of Japan.

\section{REFERENCES}

Baranton, G., Postic, D., Saint Girons, I., Boerlin, P., Piffaretti, J.-C., Assous, M. \& Grimont, P. A. D. (1992). Delineation of Borrelia burgdorferi sensu stricto, Borrelia garinii sp. nov., and group VS461 associated with Lyme borreliosis. Int $J$ Syst Bacteriol 42, 378-383.

Barbour, A. G. (1984). Isolation and cultivation of Lyme disease spirochetes. Yale J Biol Med 57, 521-525.

Barbour, A. G. \& Hayes, S. F. (1986). Biology of Borrelia species. Microbiol Rev 50, 381-400.

Blüthmann, H., Brück, D., Hübner, L. \& Schöffski, A. (1973). Reassociation of nucleic acids in solutions containing formamide. Biochem Biophys Res Commun 50, 91-97.

Burgdorfer, W., Barbour, A. G., Hayes, S. F., Benach, J. L., Grunwaldt, E. \& Davis, J. P. (1982). Lyme disease - a tick-borne spirochetosis? Science 216, 1317-1319.

Canica, M. M., Nato, F., Du Merle, L., Mazie, J. C., Baranton, G. \& Postic, D. (1993). Monoclonal antibodies for identification of Borrelia afzelii sp. nov. associated with late cutaneous manifestations of Lyme borreliosis. Scand J Infect Dis 25, 441-448.

Ezaki, T., Takeuchi, N., Liu, S. L., Kai, A., Yamamoto, H. \& Yabuuchi, E. (1988). Small-scale DNA preparation for rapid genetic identification of Campylobacter species without radioisotope. Microbiol Immunol 32, 141-150.

Ezaki, T., Hashimoto, Y. \& Yabuuchi, E. (1989). Fluorometric deoxyribonucleic acid-deoxyribonucleic acid hybridization in microdilution wells as an alternative to membrane filter hybridization in which radioisotopes are used to determine genetic relatedness among bacterial strains. Int J Syst Bacteriol 39, 224-229.

Fukunaga, M., Hamase, A., Okada, K. \& Nakao, M. (1996). Borrelia tanukii sp. nov. and Borrelia turdae sp. nov. found from ixodid ticks in Japan: rapid species identification by $16 \mathrm{~S}$ rRNA gene-targeted PCR analysis. Microbiol Immunol 40, 877-881. 
Hovind-Hougen, K., Åsbrink, E., Stiernstedt, G., Steere, A. C. \& Hovmark, A. (1986). Ultrastructural differences among spirochetes isolated from patients with Lyme disease and related disorders, and from Ixodes ricinus. Zentbl Bakteriol Mikrobiol Hyg A 263, 103-111.

Johnson, R. C., Schmid, G. P., Hyde, F. W., Steigerwalt, A. G. \& Brenner, D. J. (1984). Borrelia burgdorferi sp. nov.: etiologic agent of Lyme disease. Int J Syst Bacteriol 34, 496-497.

Kawabata, H., Masuzawa, T. \& Yanagihara, Y. (1993). Genomic analysis of Borrelia japonica sp. nov. isolated from Ixodes ovatus in Japan. Microbiol Immunol 37, 843-848.

Kee, S. H., Yoon, J. H., Oh, H. B., Park, Y. H., Kim, Y. W., Cho, M. K., Park, K. S. \& Chang, W. H. (1996). Genetic analysis of Borrelia burgdorferi sensu lato in Korea using genomic hybridization and 16S rRNA gene sequence determination. Microbiol Immunol 40, 599-605.

Le Fleche, A., Postic, D., Girardet, K., Peter, O. \& Baranton, G. (1997). Characterization of Borrelia lusitaniae sp. nov. by $16 \mathrm{~S}$ ribosomal DNA sequence analysis. Int $J$ Syst Bacteriol 47, 921-925.

Li, M., Masuzawa, T., Takada, N. \& 7 other authors (1998). Lyme disease Borrelia species in northeastern China resemble those isolated from far eastern Russia and Japan. Appl Environ Microbiol 64, 2705-2709.

Marconi, R. T., Liveris, D. \& Schwartz, I. (1995). Identification of novel insertion elements, restriction fragment length polymorphism patterns, and discontinuous 23S rRNA in Lyme disease spirochetes: phylogenetic analysis of rRNA genes and their intergenic spacers in Borrelia japonica sp. nov. and genomic group 21038 (Borrelia andersonii sp. nov.) isolates. $J$ Clin Microbiol 33, 2427-2434.

Masuzawa, T., Okada, Y., Yanagihara, Y. \& Sato, N. (1991). Antigenic properties of Borrelia burgdorferi isolated from Ixodes ovatus and Ixodes persulcatus in Hokkaido, Japan. J Clin Microbiol 29, 1568-1573.

Masuzawa, T., Komikado, T., Iwaki, A., Suzuki, H., Kaneda, K. \& Yanagihara, Y. (1996a). Characterization of Borrelia sp. isolated from Ixodes tanuki, I. turdus, and I. columnae in Japan by restriction fragment length polymorphism of $r r f(5 \mathrm{~S})-r r l(23 \mathrm{~S})$ intergenic spacer amplicons. FEMS Microbiol Lett 142, 77-83.

Masuzawa, T., Suzuki, H., Kawabata, H., Ishiguro, F., Takada, N. \& Yanagihara, Y. (1996b). Characterization of Borrelia spp. isolated from the tick, Ixodes tanuki and small rodents in Japan. $J$ Wildl Dis 32, 565-571.

Masuzawa, T., Wilske, B., Komikado, T. \& 9 other authors (1996c). Comparison of OspA serotypes for Borrelia burgdorferi sensu lato from Japan, Europe and North America. Microbiol Immunol 40, 539-545.

Masuzawa, T., Fukui, T., Miyake, M., Oh, H.-B., Cho, M.-K., Chang,
W.-H., Imai, Y. \& Yanagihara, Y. (1999). Determination of members of a Borrelia afzelii-related group isolated from Ixodes nipponensis in Korea as Borrelia valaisiana. Int J Syst Bacteriol 49, 1409-1415.

Masuzawa, T., Pan, M.-J., Kadosaka, T., Kudeken, M., Takada, N., Yano, Y., Imai, Y. \& Yanagihara, Y. (2000). Characterization and identification of Borrelia isolates as Borrelia valaisiana in Taiwan and Kinmen Islands. Microbiol Immunol 44, 1003-1009.

Noguchi, T., Kumagai, M. \& Kuninaka, A. (1988). Analysis of base composition of sequenced DNAs by high performance liquid chromatography of their nuclease p1 hydrolysate. Agric Biol Chem 52, 2355-2356.

Oliver, J. H., Jr, Owsley, M. R., Hutcheson, H. J., James, A. M., Chen, C., Irby, W. S., Dotson, E. M. \& McLain, D. K. (1993). Conspecificity of the ticks Ixodes scapuralis and I. dammini (Acari: Ixodidae). J Med Entomol 30, 54-63.

Postic, D., Assous, M. V., Grimont, P. A. D. \& Baranton, G. (1994). Diversity of Borrelia burgdorferi sensu lato evidenced by restriction fragment length polymorphism of $r r f(5 \mathrm{~S})-r r l$ (23S) intergenic spacer amplicons. Int J Syst Bacteriol 44, 743-752.

Postic, D., Ras, N. M., Lane, R. S., Hendson, M. \& Baranton, G. (1998). Expanded diversity among Californian borrelia isolates and description of Borrelia bissettii sp. nov. (formerly Borrelia group DN127). J Clin Microbiol 36, 3497-3504.

Saitou, N. \& Nei, M. (1987). The neighbor-joining method: a new method for reconstructing phylogenetic trees. Mol Biol Evol 4, 406-425.

Steere, A. C. (1989). Lyme disease. New Engl J Med 321, 586-596.

Takada, N., Ishiguro, F., Fujita, H., Wang, H.-P., Wang, J.-C. \& Masuzawa, T. (1998). Lyme disease spirochetes in ticks from northeastern China. J Parasitol 84, 499-504.

Thompson, J. D., Gibson, T. J., Plewniak, F., Jeanmougin, F. \& Higgins, D. G. (1997). The CLUSTAL_X windows interface: flexible strategies for multiple sequence alignment aided by quality analysis tools. Nucleic Acids Res 25, 4876-4882.

Wang, G., van Dam, A. P., Le Fleche, A., Postic, D., Peter, O., Baranton, G., de Boer, R., Spanjaard, L. \& Dankert, J. (1997). Genetic and phenotypic analysis of Borrelia valaisiana sp. nov. (Borrelia genomic groups VS116 and M19). Int J Syst Bacteriol 47, 926-932.

Yano, Y., Takada, N. \& Ishiguro, F. (1997). Location and ultrastructure of Borrelia japonica in naturally infected Ixodes ovatus and small mammals. Microbiol Immunol 41, 13-19.

Zung, J. L., Siewengrub, S., Rudzinska, M. A., Spielman, A., Telford, S. R. \& Piesman, J. (1989). Fine structural evidence for the penetration of the Lyme disease spirochete Borrelia burgdorferi through the gut and salivary tissues of Ixodes dammini. Can J Zool 67, 1737-1748. 